\title{
Reactie
}

\section{Kanttekeningen bij de Utrechtse kantorenaanpak}

Dr. mr. F.A.G. (Frank) Groothuijse en dr. mr. D. (Daan) Korsse*

\section{Inleiding}

Henk de Vries houdt in zijn bijdrage in dit tijdschrift een warm pleidooi voor de anpak van de provincie Utrecht om de planologische overcapaciteit voor grote kantoren in de provincie te reduceren. ${ }^{1}$ Dat deze overcapaciteit een groot probleem is dat op provinciaal niveau moet worden aangepakt, zijn wij met De Vries eens. Ook hebben wij waardering voor het ontwikkelen van een vernieuwende en creatieve aanpak waarmee de provincie de planreductie wil bewerkstelligen. Daarbij is nog van belang dat er in (bepaalde gebieden in) Nederland niet alleen sprake is van planologische overcapaciteit voor grote kantoren, maar ook voor bedrijfsterreinen $^{2}$ en detailhandel. ${ }^{3}$ De door De Vries geschetste aanpak zou dus mogelijk breder kunnen worden ingezet om andere vormen van planologische overcapaciteit te reduceren. In deze reactie willen wij echter een aantal kanttekeningen plaatsen bij de door De Vries beschreven methode waarmee het Utrechtse kantorenbeleid zal worden vormgegeven. Daarbij staat de vraag centraal of

* Dr. mr. F.A.G. (Frank) Groothuijse is als universitair hoofddocent verbonden aan het Utrecht Centre for Water, Oceans and Sustainability Law van de Universiteit Utrecht. Dr. mr. D. (Daan) Korsse is als universitair docent verbonden aan het Utrecht Centre for Water, Oceans and Sustainability Law van de Universiteit Utrecht.

1. H.J. de Vries, De vernieuwende aanpak van de kantorenleegstand door de provincie Utrecht. Een aanpak die onder de Omgevingswet niet meer op vergelijkbare wijze mogelijk is, tenzij alsnog de reikwijdte van het projectbesluit wordt verbreed!, TO 2015, afl. 3 p. 113-132.

2. Zie o.m. de brief van de minister van lenM van 7 maart 2014, IENM/ BSK-2014/50506

3. Zie <www.compendiumvoordeleefomgeving.nl/indicatoren/nl2151Leegstand-winkels.html?i=36-177> het Utrechtse instrument van het inpassingsplan daarvoor het meest geschikt is.

\section{Strekking van de Utrechtse kantorenaanpak}

De Utrechtse kantorenaanpak houdt kort gezegd in dat provinciale staten (PS) een inpassingsplan zullen vaststellen waarmee op ten minste twintig locaties de onbenutte planologische mogelijkheden worden geschrapt om kantoorgebouwen op te richten met een grotere oppervlakte dan $1500 \mathrm{~m}^{2}$. Per locatie wordt door de provincie onderzocht hoeveel behoefte er nog is aan de onbenutte bouwtitels en welke hoeveelheid plancapaciteit kan verdwijnen. Om het risico op planschadeclaims weg te nemen is voorzienbaarheid gecreëerd door het inpassingsplan aan te kondigen in een provinciale structuurvisie, de Thematische Structuurvisie Kantoren. Wie voor de terinzagelegging van het ontwerp-inpassingsplan in 2017 geen serieuze plannen heeft om daadwerkelijk kantoren te gaan ontwikkelen, zal wegens passieve risicoaanvaarding geen anspraak kunnen maken op een planschadevergoeding. Vanaf het moment dat het ontwerp-inpassingsplan ter inzage ligt, dienen nieuwe aanvragen om een omgevingsvergunning voor het bouwen van een kantoor met een grotere oppervlakte dan $1500 \mathrm{~m}^{2}$ te worden aangehouden, om vervolgens te worden afgewezen als het inpassingsplan in werking treedt. De gemeenteraad krijgt zijn bestemmingsplanbevoegdheid weliswaar direct terug, maar kan niet opnieuw voorzien in de bouw van grote kantoren. De 
Provinciale Ruimtelijke Verordening 2013 staat daaraan in de weg. ${ }^{4}$

De Vries schetst in zijn artikel twee paden die bij het wegbestemmen van de overtollige plancapaciteit bewandeld kunnen worden. In de eerste plaats kan met het inpassingsplan ter plaatse een aanduiding worden toegevoegd aan het planologisch regime, met daaraan gekoppeld een verbod op de bouw van kantoren groter dan $1500 \mathrm{~m}^{2} .{ }^{5} \mathrm{Er}$ wordt als het ware voorzien in een aanvullende planregel waarmee de oppervlakte per pand wordt gemaximaliseerd. In de tweede plaats kan met het inpassingsplan de niet-gerealiseerde kantoorbestemming worden wegbestemd door aan de gronden een 'neutrale bestemming' toe te kennen. De bestaande feitelijke situatie wordt dan als zodanig bestemd, waardoor het bouwen van kantoren in het geheel onmogelijk wordt. ${ }^{6}$

De Vries ziet de snelheid waarmee de overtollige mogelijkheden voor de bouw van grote kantoren worden geschrapt als een belangrijk voordeel van de Utrechtse kantorenaanpak. Met het inpassingsplan wordt alle plancapaciteit binnen de provincie in één keer gereduceerd en tegen die reductie staat maar één keer rechtsbescherming open. ${ }^{7}$ Bovendien maakt het planologisch regime na de inwerkingtreding van het inpassingsplan direct duidelijk dat de bouw van grote kantoorruimtes niet mogelijk is. Dat komt de rechtszekerheid ten goede, aldus De Vries.

\section{Kanttekeningen bij de Utrechtse kantorenaanpak}

Bij de voordelen van de Utrechtse kantorenaanpak die door De Vries worden genoemd, is in ieder geval een drietal kanttekeningen te plaatsen. In de eerste plaats moet worden bedacht dat een inpassingsplan net als een bestemmingsplan moet voldoen aan 'een goede ruimtelijke ordening'. Dat betekent dat het onderzoek dat aan het inpassingsplan ten grondslag ligt, zich niet mag beperken tot de behoefte aan plancapaciteit die nog bestaat op een bepaalde locatie, maar ook moet zijn gericht op de ruimtelijke situatie die ter plaatse ontstaat als de planreductie wordt doorgevoerd. Daarbij rijst bijvoorbeeld de vraag of reeds gebouwde kantoorruimtes nog wel aantrekkelijk zijn als de aanvullende kantoren op de belendende percelen nooit worden gebouwd. Bij een maximalisatie van de kantoorvloeroppervlakte tot $1500 \mathrm{~m}^{2}$ ontstaan met het oog op een goede ruimtelijke ordening bovendien vragen bij de uitvoerbaarheid van de 'resterende' bestemming. In dat geval schrapt het

4. Deze verordening is vastgesteld op grond van art. 4.1 lid 1 Wro en bevat zogenoemde instructieregels omtrent de inhoud van bestemmingsplannen die in acht moeten worden genomen door de gemeenteraad.

5. De Vries 2015, p. 120-121.

6. De Vries 2015, p. 121.

7. De Vries 2015, p. 124. provinciebestuur immers niet alleen bouwmogelijkheden voor grote kantoren, maar 'creëert' het tegelijkertijd tal van mogelijkheden voor de bouw van kleine kantoren. Met het oog op een goede ruimtelijke ordening moet dan wel aannemelijk zijn dat er behoefte is aan dergelijke mogelijkheden en dat zij binnen de planperiode gerealiseerd zullen worden. Is dat niet het geval, dan ligt het toekennen van een 'neutrale' bestemming meer voor de hand.

In de tweede plaats is van belang dat het inpassingsplan slechts een eerste stap vormt in een keten van planologische besluitvorming waarmee de locaties in kwestie een nieuwe bestemming krijgen. Het idee is niet voor niets dat de gemeenteraad zijn bestemmingsplanbevoegdheid direct na de inwerkingtreding van het inpassingsplan weer terugkrijgt. Zeker de 'neutrale' bestemming heeft een voorlopig karakter. Maar ook in het geval dat de kantoorvloeroppervlakte wordt gemaximaliseerd op $1500 \mathrm{~m}^{2}$ is het de vraag wat de gemeente opschiet met deze bebouwingsmogelijkheden, en of zij ter plaatse niet veel liever een volledig andere bestemming ziet. In beide gevallen wordt dus niet veel meer duidelijk gemaakt dan dat ter plaatse geen grote kantoren mogen worden geplaatst. Het is vervolgens aan de gemeenteraad om te bepalen waarvoor de locatie dan wél mag worden gebruikt en om een meer definitieve bestemming toe te kennen. De Vries geeft dus een vertekend beeld van de snelheid waarmee het inpassingsplan duidelijkheid en rechtszekerheid biedt. De eigenaren van de percelen en de gebruikers van de omliggende gronden weten weliswaar snel dat er geen grote kantoren meer mogen worden gebouwd, maar zij weten pas echt waar zij aan toe zijn als ook de gemeentelijke vervolgbesluitvorming is afgerond. En hoewel het klopt dat tegen de planreductie slechts één keer beroep openstaat, kan tegen de gemeentelijke vervolgbesluitvorming natuurlijk gewoon worden opgekomen. Over de hele linie beschouwd is dus wel degelijk sprake van dubbele rechtsbescherming. Daar heeft de provincie weliswaar geen last van, maar grondeigenaren en derden-belanghebbenden wel.

In de derde plaats lijkt het erop dat het inpassingsplan verder gaat dan nodig is om het betrokken provinciaal belang te beschermen. Het kantorenbeleid maakt duidelijk dat het provinciebestuur zich uitsluitend verantwoordelijk acht voor het schrappen van overtollige plancapaciteit. Bij de nieuwe - weliswaar voorlopige - neutrale bestemming die met het inpassingsplan wordt toegekend, bestaat als zodanig geen provinciaal belang, en bij bebouwingsmogelijkheden voor kleine kantoren evenmin. Het is immers juist een gemeentelijke verantwoordelijkheid om te bepalen waarvoor de grond in de toekomst wél gebruikt mag worden. Dat roept de vraag op of het provinciebestuur dergelijke wijzigingen wel 
mag aanbrengen in het planologisch regime. ${ }^{8}$ Deze vraag is niet louter van principiële aard. De keuze voor het inpassingsplaninstrument kan ook praktische consequenties hebben voor de mogelijkheid van het gemeentebestuur om ter plaatse in een andere ontwikkeling te voorzien. Wij wijzen er bijvoorbeeld op dat als ervoor gekozen wordt om een 'neutrale' bestemming' toe te kennen, de gemeenteraad bij de vervolgbesluitvorming vrijwel zeker de ladder duurzame verstedelijking zal moeten doorlopen. Met het inpassingsplan worden de bestaande bebouwingsmogelijkheden immers tot nul gereduceerd, zodat een daaropvolgend bestemmingsplan dat voorziet in een stedelijke ontwikkeling per definitie zorgt voor nieuw ruimtebeslag.

Ook voor planschade kan dit gevolgen hebben. De nieuwe bestemming die de gemeenteraad wil toekennen in het bestemmingsplan kan immers ten opzichte van de 'neutrale' bestemming in het inpassingsplan (bijvoorbeeld 'Groen' zonder bouwvlakken) nadelige gevolgen hebben voor omwonenden. Daardoor kan de gemeente worden geconfronteerd met planschade die eigenlijk het gevolg is van het toekennen van de 'neutrale' bestemming in het inpassingsplan. Als de gemeente namelijk in de gelegenheid was gesteld om zelf de bebouwingsmogelijkheden voor grote kantoren te vervangen door andere bebouwings- en gebruiksmogelijkheden, zoals woondoeleinden of gemengde doeleinden, had deze planschade (en bijbehorende procedures) mogelijk voorkomen kunnen worden. Om deze planschade te voorkomen stelt De Vries voor om actieve risicoaanvaarding in het leven te roepen door in de toelichting van het inpassingsplan op te nemen dat in de toekomst rekening moet worden gehouden met het toekennen van stedelijke functies aan de betreffende gronden die qua ruimtelijke uitstralingseffecten vergelijkbaar zijn met de bouw- en gebruiksmogelijkheden van het nu met het inpassingsplan geschrapte bebouwingsvlak'. ${ }^{10}$ Naar ons oordeel kan daarmee echter geen voorzienbaarheid in het leven worden geroepen voor de eigenaren van omliggende percelen die dat ten tijde van de terinzagelegging van het ontwerp-inpassingsplan al waren, aangezien zij op het moment van hun investering geen rekening konden houden met het in de toelichting van het inpassingsplan aangekondigde beleidsvoornemen. ${ }^{11}$ Voorzienbaarheid kan alleen in het leven worden geroepen voor grondeigenaren die rekening konden houden met het beleidsvoornemen. Daarbij komt dat wij ons afvragen of het beleidsvoornemen concreet genoeg is ${ }^{12}$ en of de voorzienbaarheid ook in dit geval door PS in het leven kan worden geroepen, aangezien de gemeenteraad beleidsvrijheid heeft ten aanzien van de vraag of er een nieuwe bestemming aan de gronden zal worden toegekend, en zo ja, welke bestemming dat zal zijn.

Deze kanttekeningen roepen de vraag op of het inzetten van een inpassingsplan inderdaad de meest efficiënte methode is om de planreductie te bewerkstelligen. De Wet ruimtelijke ordening (Wro) voorziet namelijk ook in een ander instrument waarmee het Utrechtse kantorenbeleid verwezenlijkt kan worden, namelijk instructieregels.

\section{Instructieregels als alternatief}

De door de provincie Utrecht gewenste reductie van de plancapaciteit voor de bouw van grote kantoren kan ook worden gewaarborgd met instructieregels als bedoeld in art. 4.1 lid 1 Wro. In een instructieregel kan worden voorgeschreven dat op specifieke locaties onbenutte plancapaciteit voor de bouw van grote kantoren uit het bestemmingsplan moet worden geschrapt. Op grond van art. 4.1 lid 2 Wro zijn de gemeenteraden verplicht om hun bestemmingsplannen binnen de termijn van in beginsel één jaar aan de instructieregel aan te passen. Om te voorkomen dat in de tussengelegen periode nog nieuwe grote kantoren worden gebouwd, kunnen op grond van art. 4.1 lid 3 Wro tijdelijke bouwverboden worden opgenomen in een instructieregel. Die provinciale bouwverboden zijn, evenals bestemmingsplanregels, een toetsingsgrond voor omgevingsvergunningen voor het bouwen van een bouwwerk. ${ }^{13}$ Met regels op grond van art. 4.1 lid 3 Wro kan de bouw van kantoren met een grotere oppervlakte dan $1500 \mathrm{~m}^{2}$ worden tegengehouden tot het moment dat de gemeenteraad de mogelijkheden daarvoor uit het planologisch regime
8. Dat de Afdeling bestuursrechtspraak slechts marginaal toetst of daadwerkelijk een provinciaal belang aanwezig is en dat het inpassingsplan dus niet snel over deze voorwaarde zal struikelen, neemt natuurlijk niet weg dat het plan door een provinciaal belang gedragen moet kunnen worden en dat PS dit moeten kunnen motiveren.

9. Daarbij is natuurlijk wel van belang welke 'neutrale' bestemming aan de gronden wordt toegekend. Wat een neutrale bestemming inhoudt, is ons nog niet helemaal duidelijk.

10. De Vries 2015, p. 121
11. Dat neemt niet weg dat hun in bepaalde omstandigheden normaal maatschappelijk risico kan worden tegengeworpen of dat ten tijde van de investering van de perceeleigenaren sprake was van voorzienbare minder gunstige of even ongunstige ontwikkelingen als de nieuwe bestemming, zodat niet in alle gevallen (volledige) planschade zal hoeven te worden toegekend. Zie voor deze 'ondoorbroken voorzienbaarheid' ABRvS 1 december 2011, AB 2012/327 m.nt. G.M. van den Broek, waarin de Afdeling oordeelt dat voor het antwoord op de vraag of een planologische verandering buiten het eigen perceel voor een aanvrager voorzienbaar was, alleen de planologische situatie ten tijde van de koop van het eigen perceel van belang is. Een tussentijdse voor de perceeleigenaren gunstige bestemming doorbreekt de voorzienbaarheid dus niet, zodat hun bij een latere nadelige wijziging nog steeds voorzienbaarheid kan worden tegengeworpen.

12. Zie bijv. ABRvS 17 augustus 2005, AB 2006/164 m.nt. G.M. van den Broek.

13. Zie art. 2.10 lid 1 onder c Wabo. 
heeft geschrapt. ${ }^{14} \mathrm{Om}$ de door de provincie gewenste voorzienbaarheid te creëren en planschadevergoedingen ${ }^{15}$ te omzeilen, kan worden bepaald dat het bouwverbod pas in werking treedt op het moment dat van passieve risicoaanvaarding kan worden gesproken. In de verordening zou kunnen worden bepaald dat het bouwverbod pas anderhalf jaar na openbaarmaking van het concrete beleidsvoornemen tot de planreductie ingaat.

De Vries acht het gebruik van de instructieregelbevoegdheid geen geschikt alternatief voor het vaststellen van een inpassingsplan. Hij wijst daarvoor op het feit dat het dan aan de gemeenteraden is om hun bestemmingsplannen te herzien en de overtollige plancapaciteit te schrappen. Tegen elk bestemmingsplan kan beroep worden ingesteld en in dat beroep kan de gerealiseerde planreductie ter discussie worden gesteld. Daar komt volgens De Vries nog bij dat als gemeenten nalaten om een nieuw bestemmingsplan vast te stellen, gedeputeerde staten gehouden zijn om een indeplaatsstellingsbesluit te nemen in verband met gemeentelijke taakverwaarlozing. Daarvoor moet een langdurig en complex besluitvormingsproces worden doorlopen. In de tussentijd blijven de bestemmingsplannen gewoon de mogelijkheid bieden om grote kantoren te bouwen, hetgeen ten koste gaat van de rechtszekerheid en de duidelijkheid van het planologisch regime, aldus De Vries. ${ }^{16}$ Hij stelt:

'Wanneer zich de situatie voordoet dat er gemeentebesturen zijn die volgens de regelen der kunst uitvoering geven aan de door het provinciebestuur gegeven instructie, maar andere gemeentebesturen dat niet of niet naar behoren doen, waardoor er sprake is van taakverwaarlozing en GS tot een IBT-interventie overgaan, verschuiven bedoelde duidelijkheid en rechtszekerheid zo ongeveer naar achter de horizon.' ${ }^{17}$

Op dit punt verschillen wij van mening met De Vries. Wij zien niet in waarom provinciale bouwverboden in een verordening minder duidelijk of rechtszeker zijn dan het schrappen van bouwmogelijkheden voor grote kantoren met een inpassingsplan. Het resultaat is immers precies hetzelfde: de aanvraag om een bouwvergunning voor de bouw van een groot kantoor moet geweigerd worden. Met een provinciaal bouwverbod wordt die rechtszekerheid bovendien juist sneller verkregen, omdat daartegen, anders dan tegen een inpassingsplan, geen rechtsbescherming openstaat.

Dat het vervolgens aan de gemeenteraad is om de plancapaciteit uit het planologisch regime te schrappen, zien wij eerder als een voordeel dan als een nadeel. Deze werkwijze erkent dat sprake is van een keten van plano-

14. Zie voor een mooie illustratie van de werking van regels op grond van art. 4.1 lid 3 Wro ABRvS 3 juni 2015, TBR 2015/146 m.nt. D. Korsse.

15. De instructieregel in de zin van art. 4.1 lid 3 Wro is in art. $6.1 \mathrm{lid} 2$ onder e Wro aangewezen als een planschadeoorzaak.

16. De Vries 2015, p. 124-125.

17. De Vries 2015, p. 125 logische besluitvorming, waarin het provinciebestuur aanstuurt op het verdwijnen van bebouwingsmogelijkheden voor grote kantoren en de gemeenteraad de desbetreffende gronden vervolgens een nieuwe bestemming geeft. Dat heeft als voordeel dat in het totale proces sprake is van slechts één rechtsbeschermingsmoment, namelijk tegen het bestemmingsplan waarin de grond zijn definitieve bestemming krijgt. Het provinciale bouwverbod kan daarin bij wijze van exceptie aan de orde worden gesteld. Een ander voordeel is dat het provinciebestuur zich in deze werkwijze uitdrukkelijk beperkt tot zijn provinciaal belang dat de overtollige plancapaciteit voor grote kantoren verdwijnt, zonder zich te mengen in een - al dan niet voorlopige - nieuwe bestemming ter plaatse.

Naar de letter van de wet heeft De Vries gelijk dat het provinciebestuur verplicht is om een indeplaatsstellingsbesluit te nemen als de gemeenteraad nalaat de bestemmingsplanwijziging door te voeren die in de instructieregel wordt voorgeschreven. Wij betwijfelen echter of de soep zo heet moet worden gegeten als zij wordt opgediend. Zolang de overtollige plancapaciteit in weerwil van de instructieregel blijft bestaan, blijft ook het provinciale bouwverbod van kracht. Er kunnen linksom of rechtsom dus geen nieuwe grote kantoren bij komen. Als het provinciebestuur het planologisch regime toch graag veranderd ziet, dan hoeft het daarvoor geen indeplaatsstellingsbesluit te nemen, maar zouden PS alsnog een inpassingsplan kunnen vaststellen. ${ }^{18}$

Kortom: een instructieregel met een daaraan gekoppeld bouwverbod biedt evenals een inpassingsplan per direct duidelijkheid over wat niet mag, en in beginsel relatief snel rechtszekerheid over wat wel mag (namelijk binnen de implementatietermijn van één jaar). De keuze voor een instructieregel verdient naar ons oordeel de voorkeur, omdat de provinciale ingreep daarmee niet verder gaat dan nodig en de stap van de 'voorlopige' bestemming (in de vorm van een neutrale bestemming of een maximalisatie van de vloeroppervlakte van nieuwe kantoren) wordt overgeslagen, waardoor dubbele totstandkomings- en rechtsbeschermingsprocedures worden voorkomen.

\section{De Utrechtse kantorenaanpak onder de Omgevingswet}

Volgens De Vries zal de Utrechtse kantorenaanpak niet meer mogelijk zijn onder de Omgevingswet (Ow), omdat daartoe een met het inpassingsplan vergelijkbaar instrument ontbreekt. Het projectbesluit op grond van art. 5.44 Ow komt volgens hem niet in aanmerking,

18. Het feit dat de gemeenteraad uit eigen beweging niet is overgegaan tot het wijzigen van het planologisch regime betekent dat de inzet van dit zwaardere middel beter kan worden gemotiveerd. 
omdat daarmee uitsluitend projecten kunnen worden gerealiseerd en geen activiteiten kunnen worden geweerd. ${ }^{19}$ Ook de in art. 4.2 lid 2 Ow geboden mogelijkheid om in een provinciale omgevingsverordening functies toe te kennen aan locaties voldoet niet, omdat daaraan naar de mening van De Vries zware motiveringseisen zijn verbonden. Om functies toe te kennen aan locaties moet het provinciebestuur namelijk niet alleen onderbouwen dat aan het subsidiariteitsvereiste is voldaan dat in art. $2.3 \mathrm{Ow}$ is neergelegd, maar op grond van art. 4.2 lid $2 \mathrm{Ow}$ ook dat de planreductie niet doelmatig of doeltreffend met een instructieregel of een instructiebesluit kan worden gerealiseerd. Omdat niet zeker is hoe indringend de Afdeling bestuursrechtspraak aan deze motiveringsverplichtingen zal toetsen, kan art. 4.2 lid 2 Ow volgens De Vries niet worden beschouwd als een volwaardig opvolger van het inpassingsplaninstrument. ${ }^{20}$

Hoewel terugdringing van de plancapaciteit voor grote kantoren met behulp van instructieregels ook onder de Ow onze voorkeur verdient, denken wij dat de Utrechtse kantooraanpak onder de Ow mogelijk blijft. Met De Vries zijn wij van mening dat het enkel reduceren van plancapaciteit voor grote kantoren met het provinciale projectbesluit niet mogelijk is, maar wij zien nog wel steeds mogelijkheden om met behulp van de omgevingsverordening de plancapaciteit te schrappen. De zware motiveringseisen uit de $\mathrm{Ow}$ staan daaraan niet in de weg.

Art. 2.3 Ow stelt weliswaar uitdrukkelijk de eis dat de subsidiariteit, de doelmatigheid en de doeltreffendheid van de ingreep beter gemotiveerd moeten worden dan de Wro dat doet, maar dat betekent niet dat de lat inhoudelijk ook hoger wordt gelegd. Of dat het geval zal zijn, hangt af van de vraag hoe indringend de Afdeling bestuursrechtspraak aan art. 2.3 Ow zal toetsen. Wij verwachten dat de Afdeling dat terughoudend zal doen, omdat zij uitsluitend een rechtmatigheidstoetsing kan verrichten. Het subsidiariteitsvereiste laat veel beoordelingsvrijheid, want over de vraag wanneer sprake is van doeltreffendheid en doelmatigheid bepaalt de Ow niets. Wat betreft de toekenning van functies aan locaties in een omgevingsverordening komt daar nog bij dat de verordening een algemeen verbindend voorschrift is, waartegen waarschijnlijk geen rechtstreekse bestuursrechtelijke rechtsbescherming zal openstaan. De subsidiariteit van de planreductie kan dus slechts bij wijze van exceptieve toetsing aan de orde worden gesteld. ${ }^{21}$

19. De Vries 2015, p. 126

20. De Vries 2015, p. 131

21. Wij zien overigens niet in waarom tegen de toekenning van functies aan locaties in de omgevingsverordening geen bestuursrechtelijke rechtsbescherming zou worden opengesteld, aangezien tegen het huidige inpassingsplan ook beroep bij de bestuursrechter openstaat en tegen het omgevingsplan ook bestuursrechtelijke rechtsbescherming zal openstaan. Of er bestuursrechtelijke rechtsbescherming open zal staan tegen functietoekenning in de omgevingsverordening zal moeten blijken uit de Invoeringswet Omgevingswet. Zie Kamerstukken II 2013/14, 33 962 , nr. 3, p. 296 e.v.
De in art. 4.2 lid 2 Ow gestelde eis dat de planreductie niet doelmatig of doeltreffend met een instructieregel kan worden gerealiseerd, is evenmin bezwaarlijk. Het is namelijk van tweeën één. Of het Utrechtse kantorenbeleid kan niet goed met instructieregels worden verwezenlijkt, zoals De Vries meent, in welk geval de Ow er niet aan in de weg staat om de omgevingsverordening daarvoor in te zetten. Of instructieregels zijn een efficiënter middel om de planreductie te realiseren - zoals wij menen - zodat de Ow aan dat instrument de voorkeur zou moeten geven. ${ }^{22}$ Als wordt gekozen voor een aanpak met instructieregels, maar de gemeenteraad weigert deze op te volgen door de overtollige plancapaciteit in stand te laten, dan is naar ons oordeel overigens per definitie voldaan aan art. 4.2 lid 2 Ow. In dat geval is immers gebleken dat de planreductie niet doeltreffend met een instructieregel bewerkstelligd kan worden, waarna PS die reductie kunnen doorvoeren in de omgevingsverordening. Toepassing van het generieke toezichtinstrumentarium voor taakverwaarlozing is ook onder de Ow naar ons oordeel niet nodig.

Voor het verplichten tot een planreductie in instructieregels is nog wel van belang dat de Ow PS geen uitdrukkelijke bevoegdheid meer biedt om rechtstreeks werkende bouwverboden vast te stellen. Om te voorkomen dat gedurende de implementatietermijn van de instructieregels nog gebruik wordt gemaakt van bestaande bouwmogelijkheden uit het geldende omgevingsplan moet een andere weg worden bewandeld. Onder de Ow is de werkingsduur van het voorbereidingsbesluit dat PS voorafgaand aan de vaststelling van een instructieregel kunnen nemen, verlengd totdat het omgevingsplan met de desbetreffende regels in overeenstemming is gebracht. Daarnaast kan de aanhoudingsplicht voor aanvragen om een omgevingsvergunning voor een bouwactiviteit worden beperkt tot in het voorbereidingsbesluit aangegeven gevallen. PS kunnen dan ook voorafgaand aan het vaststellen van een instructieregel tot planreductie een voorbereidingsbesluit nemen met betrekking tot de bouw van grote kantoren. ${ }^{23}$ Aanvragen om een omgevingsvergunning voor het bouwen van dergelijke kantoren zullen in dat geval moeten worden aangehouden totdat het omgevingsplan in overeenstemming is gebracht met de instructieregel. ${ }^{24} \mathrm{Via}$ deze weg kan het provinciebestuur

22. Blijkens de MvA ziet de regering de instructie en de instructieregel ook als geschiktere provinciale instrumenten voor het reduceren van nietgerealiseerde plancapaciteit dan inpassingsplanbevoegdheid, omdat de beleidsvrijheid van de gemeente daardoor beter wordt gerespecteerd. Zie Kamerstukken I 2014/15, 33 962, E, p. 52-53.

23. Zie art. 4.16 lid 1 jo. art. 16.56 lid 2, 3 en 4 onder b Ow. Anders dan in het huidige voorbereidingsbesluit kan de aanhoudingsplicht voor bouwactiviteiten worden beperkt tot de daarin aangewezen gevallen (art. 4.16 lid $4 \mathrm{Ow}$ ). De bevoegdheid tot het nemen van een voorbereidingsbesluit kan worden gedelegeerd aan GS (art. 4.16 lid 3 jo. art. 4.15 lid 3 Ow). Tegen een voorbereidingsbesluit zal evenals thans het geval is geen bestuursrechtelijke rechtsbescherming openstaan (Kamerstukken II 2013/14, 33 962, nr. 3, p. 300).

24. Zie art. 4.16 lid 5 onder b Ow. De aanhoudingsplicht zal niet kunnen worden doorbroken zonder betrokkenheid van de provincie. In de uitvoeringsregelgeving zal worden voorzien in een advies- of instemmingsrecht voor de provincie. Zie Kamerstukken II 2013/14, 33 962, nr. 3, p. 147-148. 
onder de $\mathrm{Ow}$ - evenals onder de Wro - voorkomen dat er aanvragen om omgevingsvergunningen voor de bouw van grootschalige kantoren worden verleend, zolang het omgevingsplan niet aan de instructieregel is aangepast.

\section{Conclusie}

De Utrechtse kantorenaanpak is een interessante en creatieve manier om iets te doen aan overtollige plancapaciteit voor grote kantoren. Wij denken echter dat instructieregels een minder omslachtig en daardoor efficiënter instrument zijn om tot het schrappen van kantoorbestemmingen te komen. Het provinciebestuur kan hiermee hetzelfde resultaat bereiken zonder een nieuwe voorlopige - bestemming toe te kennen, met alle mogelijk nadelige gevolgen van dien. Met instructieregels wordt de ruimtelijke beleidsvrijheid van de gemeenteraad beter gerespecteerd. Bovendien wordt voorkomen dat twee planologische besluiten moeten worden genomen - en twee rechtsbeschermingsprocedures moeten doorlopen - voordat de locaties een definitieve bestemming krijgen. Ook wordt voorkomen dat de gemeente bij de toekenning van een nieuwe bestemming onnodig wordt opgezadeld met de ladder duurzame verstedelijking en planschadekwesties die indirect het gevolg zijn van het toekennen van de neutrale bestemming in het inpassingsplan. Dat wil niet zeggen dat wij geen enkele rol zien weggelegd voor het inpassingsplan bij planreductieoperaties. Het inpassingsplan kan daarbij namelijk fungeren als een stok achter de deur. De inzet van instructieregels in combinatie met extern werkende (lid 3-)regels dient echter eerst serieus te worden overwogen, voordat wordt overgegaan tot het vaststellen van een inpassingsplan.

Wij denken dat de Ow niet in de weg zal staan aan de Utrechtse kantorenaanpak, zij het dat het provinciaal instrumentarium op enkele punten gewijzigd zal worden. Onder de Ow kunnen instructieregels worden gecombineerd met een voorbereidingsbesluit, waarna de weg te bestemmen plancapaciteit niet langer kan worden benut. De omgevingsverordening neemt de plaats in van het inpassingsplan als stok achter de deur. Aan het gebruik van de omgevingsverordening zijn enkele motiveringsvereisten verbonden, maar die zijn naar onze verwachting niet onoverkomelijk. 